\title{
Imprensa Alternativa - Comentários sobre o acervo
}

Sandra Alves Horta *

\section{Resumo}

Tratamos, neste trabalho, das idéias e conceitos que embasaram a política cultural posta em prática pelo Centro de Imprensa Alternativa e Cultura Popular do RIOARTE e que resultaram na acumulação de um acervo reunido sob a rubrica Imprensa Alternativa. Este estudo tem, também, o objetivo de analisar e descrever o tratamento que foi dado a esta coleção de periódicos de forma a identificar, classificar e organizar os documentos pertencentes ao acervo do Arquivo Geral da Cidade do Rio de Janeiro e torná-los acessíveis à consulta pública na instituição e através de meio digital, bem como discutir os possíveis usos deste acervo como fonte pelos pesquisadores de várias áreas do conhecimento.

\section{Palavras-chave: Imprensa alternativa. Ditadura militar. Acervo.}

\section{Title: Alternative press - collection's commentaries}

\begin{abstract}
:
We deal here with the ideas and concepts on which were based the cultural policy carried on by the Alternative Press and Popular Culture Center that turned out to be stored under the Alternative Press Collection mark.

This work also aims to analyze and describe the visual aspects that this newspapers collection was given in order to make it easier to identify, to arrange and organize the documents belonging to the Town's Archive and that made them more accessible to public consultation inside the institution or by digital means, as well as to discuss the possible usages of this collection as a source for many knowledge areas researches.
\end{abstract}

Key-words: Alternative press. Collection. Military dictatorship.

O acervo Imprensa Alternativa foi doado ao Arquivo da Cidade pela Fundação 
RIOARTE, órgão da então Secretaria Municipal de Cultura/Prefeitura da Cidade do Rio de Janeiro, em 1992. Constava de material audiovisual e de uma hemeroteca, mas apenas os jornais e revistas serão comentados aqui. Foi acumulado por iniciativa de Maria Amélia Mello, coordenadora do Centro de Cultura Alternativa, criado em 1980, quando era presidente daquela fundação o escritor José Rubem Fonseca. O objetivo geral que inspirou a criação do Centro foi "documentar e divulgar, por meio de seminários, mostras, concursos, aspectos da cultura brasileira" e o objetivo específico "catalogar o que produziu e produz o país na imprensa alternativa e na produção cultural independente nos anos 60/80." (RIOARTE, 1982, p. 1)

De acordo com a idéia que embasava as ações do Centro, a expressão cultura alternativa remetia, no Brasil, ao final da década de 1960 e início da década de 1970, época em que começaram a surgir, em todo o país, manifestações culturais localizadas fora dos circuitos comerciais de produção e distribuição e, sobretudo, avessas ao espírito desses circuitos tradicionais. Segundo, ainda, o pensamento do Centro, imprensa, literatura, cinema, teatro, música enfrentaram nesse período condições adversas que acabaram por representar um marco importante e reflexivo na história da cultura brasileira. Neste sentido, para esse órgão, um enfoque crítico da realidade sócio-cultural dos anos de autoritarismo passaria inevitavelmente pelo estudo dessa produção (RIOARTE, 1984, p. 2).

Assim sendo, o corpo técnico do Centro de Cultura Alternativa divulgou seus objetivos nos jornais de grande tiragem do país e efetuou contatos por correspondência ou mesmo pessoalmente, tendo sido enviadas mais de duas mil cartas a intelectuais, artistas, jornalistas, entre outros. Os ideais que impulsionavam o Centro e os esforços que desenvolveram no sentido de constituir o acervo obtiveram imediata repercussão, resultando na doação de cerca de 5.000 peças, entre jornais, livros, discos, revistas, recortes, fitas, arte postal, quadrinhos, folhetos e cartazes.

Em agosto de 1984, o Centro reformulou seu conceito de cultura alternativa afirmando que as manifestações culturais à margem do sistema não representavam uma cultura alternativa à cultura dominante, mas uma cultura de resistência à 
opressão de qualquer natureza, passando então a denominar-se Centro de Imprensa Alternativa e Cultura Popular. Conceito extremamente controvertido, escapa à pretensão deste trabalho aprofundar a discussão sobre o significado de cultura popular neste ou naquele contexto. O que nos interessa é que não houve grandes alterações nas metas e nos programas do Centro, que deu continuidade à intenção de criar a "oportunidade de tornar vivo o material reunido" (RIOARTE, 1984, p.1), ultrapassando o mero registro e sua preservação. Procuraram retirar o maior rendimento do acervo, abrindo-o à pesquisa, realizando estudos, promovendo palestras, projeções cinematográficas, concursos, programa na rádio Roquete Pinto, intitulado "Segundas Intenções", visando a divulgar e manter o público informado sobre a produção da cultura de resistência, e colhendo depoimentos de compositores, teatrólogos, jornalistas, de maneira a produzir um acervo de história oral sobre o tema (RIOARTE, 1984, p. 3).

Esse acervo multimídia foi constituído entre 1980 e 1982, quando a ação da censura político-militar já se fazia menos visível sobre os meios de comunicação, devido à distensão política "lenta e gradual" iniciada em 1975, no governo do presidente Ernesto Geisel. Os anos em que a censura foi mais aguda, compreendidos entre 1968 e 1979, com a edição do Al-5 e a regulamentação da censura prévia através do Decreto $\mathrm{n}^{\circ}$ 1077, de março de 1970, tinham, enfim, de certa maneira, sido superados. Porém, a censura não fora completamente abolida, principalmente sobre a imprensa alternativa, pois apesar da suspensão à censura prévia na maioria dos jornais ocorrida em 1978, em outubro do mesmo ano o Centro de Informações do Exército (CIE) elaborou um estudo minucioso sobre a imprensa nanica, sugerindo uma série de sanções econômicas e administrativas para silenciá-la, consideradas mais eficientes e menos desgastantes que a censura político-militar ou as medidas judiciais (MARCONI, 1980, p. 136). Embora no início dos anos 1980 os tempos ainda não fossem de total normalidade democrática, já permitiam um olhar sobre o passado recente e uma tentativa de resgate, de análise e compreensão do que o Centro denominara imprensa alternativa.

Voltando a 1964, na medida em que alguns órgãos da Grande Imprensa criaram condições para o golpe, outros aderiram no primeiro momento, outros ainda resolveram se omitir ou mesmo colaborar para sobreviver, deu-se o ensejo para o 
surgimento de veículos que adotaram uma postura de independência em relação à ideologia dominante. Por outro lado, a própria ação da censura, impedindo jornalistas de trabalhar, cerceando a informação, impondo silêncio sobre temas de interesse nacional, anulando direitos essenciais dos cidadãos, incentivou a proliferação desses periódicos. Antônio Callado explicita bem essa situação quando diz que: "contra sua própria vontade, frustrando suas mais caras intenções, a censura, perseguindo jornalistas, cria um prego, uma pedra, no próprio sapato, ou bota: cria a imprensa alternativa, nanica." (CALLADO, 1980).

Entre 1964 e 1980, cerca de 160 periódicos alternativos surgiram e desapareceram por motivos vários, que vão desde a censura, que atingiu os meios de comunicação em geral (rádio, televisão, editoras, jornais, teatro, cinema), à ação violenta dos órgãos de repressão, invadindo as redações, atacando bancas de jornal, apreendendo as edições, suspendendo a circulação, dificultando a obtenção de empréstimos, ameaçando os anunciantes, acabando por tornar esses periódicos inviáveis economicamente. A história dos jornais políticos mais conhecidos, como Opinião e Movimento, já foi escrita. No entanto, outros tão combativos como 0 Trabalho e como $O$ Trabalhador que, respectivamente, denunciaram "O circo das eleições" (O CIRCO..., 1978, p. 1), apontando a farsa democrática na sucessão do presidente Geisel ou defendiam a formação do Partido dos Trabalhadores (O PARTIDO..., 1979, p. 1); como Ex, depois Extra, posteriormente Mais Um, Politika, Lampião, Crítica, De Fato, Contestado, o Inimigo do Rei, de linha anarquista, que tratavam de assuntos temerários para a época como as matérias "Hora de censurar a censura" (HORA..., 1975, p. 1), "O ritual da aflição nos cárceres políticos" (O RITUAL..., 1978, p 17), "Cada vez mais difícil ter uma 'opinião' em 'movimento'" (CADA..., 1976, p.1), em alusão à censura nos dois semanários, aguardam pelos pesquisadores que desejem narrar suas trajetórias.

Segundo Patrícia Marcondes de Barros, ainda colaboraram para o colapso da imprensa nanica problemas internos tais como:

o modelo ético-político que consistia no repúdio ao lucro e, mesmo ao desprezo por questões administrativas, de organização e comercialização. Paradoxalmente, a insistência numa distribuição nacional antieconômica, a incapacidade de formar grandes bases de 
leitores-assinantes e certo triunfalismo em relação aos efeitos da censura contribuíram para fazer da imprensa alternativa não uma formação permanente, mas sim, algo provisório, frágil, vulnerável não só aos ataques de fora como às suas próprias contradições. (BARROS, 2004, p. 3).

Alguns estudiosos do tema afirmam que os jornais alternativos desapareceram principalmente por causa da abertura política, perdendo então sua razão de ser, já que sua principal função era ser um canal de resistência à ditadura. Bernardo Kucinski vai mais além e diz que problemas partidários ou o sectarismo das correntes políticas foram causas mais eficientes que o fim do regime de arbítrio para calar essa imprensa (KUCINSKI, 2003, p. 36).

Seja qual for o motivo que tenha freado o impulso de criar órgãos de informação, denúncia e discussão independentes e soberanos após os anos mais duros do regime de exceção, sabemos que a imprensa alternativa não é um fenômeno apenas do período da ditadura civil-militar, ela vicejou em diversos momentos da vida política e social do país e no exterior. São inúmeros os exemplos de jornais de contestação no Império, de pasquins que atuaram corajosamente no período regencial, de veículos anarquistas publicados nos primeiros anos da República. Ainda hoje a imprensa alternativa subsiste principalmente na Internet, revelando que esse espírito de oposição e de dissensão nunca deixou de existir, mas que conheceu seus momentos de maior expansão e vigor entre o Al-5, em 1968, e a Lei da Anistia, em 1979.

Diante desse quadro, o Centro de Imprensa Alternativa e Cultura Popular decidiu constituir um acervo de imprensa alternativa com a intenção de preservar o registro de um momento memorável de resistência ao arbítrio, no qual essa imprensa representou um papel significativo. Conseguiu, assim, o feito notável de acumular cerca de 1300 títulos de jornais, revistas e textos mimeografados, publicados num período que ultrapassa os 20 anos da ditadura militar, estendendo-se de 1955 a 2002, e que vão desde publicações que veiculam opiniões de vários grupos de esquerda, de partidos políticos, sindicatos, grêmios e diretórios estudantis, jornais de minorias (negro, mulher e homossexuais) a jornais de bairro, revistas literárias, acadêmicas, de defesa do meio-ambiente, de humor, esotéricas, de parapsicologia, 
psicologia e culturais (artes plásticas, cinema, música popular e erudita, teatro, movimentos de contra-cultura e underground.). Esse trabalho foi, à época, pioneiro. Hoje a Universidade de Brasília e a Universidade de Campinas possuem acervos significativos sobre a imprensa alternativa.

Um conjunto tão heterogêneo - uma vez que periódicos que abrangem um período extenso, assuntos diferentes, origens e objetivos distintos encontram-se reunidos sob o título Imprensa Alternativa - nos remete à questão da conceituação. Qual o conceito de imprensa alternativa que presidia a política cultural e as ações do Centro de Imprensa Alternativa e Cultura Popular e que orientou a formação desse acervo? Para o jornalista Maurício Azedo, quando se fala de imprensa alternativa:

a tendência dominante parece ser a de se considerar como imprensa alternativa os veículos de natureza política que se colocaram em oposição ao sistema implantado no país a partir de 1964 e 1968, mas, essa definição não abrange toda a riqueza do fenômeno, que não se manifestou apenas no campo político. (1991 apud KUCINSKI, 2003).

Ilustra essa associação comumente feita entre Imprensa Alternativa e grupos de esquerda a entrevista concedida recentemente por Reinaldo Azevedo, por ocasião do fechamento do jornal Primeira Leitura. O citado jornalista respondeu a uma pergunta do repórter - que caracterizou o jornal que ele dirigia como alternativo, talvez por fazer contundente e sistemática oposição ao governo atual - afirmando: "Eu rejeito o 'alternativo' para o que eu fazia. O termo está excessivamente ligado à imprensa de esquerda, que eu nunca fiz." (AZEVEDO, 2006). No entanto, para muitos especialistas, essa vinculação não é necessária, pois jornais de bairro, revistas literárias, veículos estudantis e de minorias (negro, mulher e homossexuais) estão também incluídos nessa categoria e, na maioria das vezes, sua contestação não passava pela questão política stricto sensu.

Ao exporem nos relatórios seus objetivos e ações, e ao justificá-los, o Centro de Imprensa Alternativa e Cultura Popular nos permite empreender uma leitura do que os intelectuais que o presidiam concebiam como imprensa alternativa. Analisando a produção dos anos 70/80, o relatório do Centro dizia: 
o super-8 estava na ordem do dia. Criava-se uma nova fonte de produção que arregimentava todo um novo conjunto de produtos. De um lado, os movimentos de rebelião da juventude, designados genérica e mundialmente com o rótulo de contra-cultura. Situavase aí o questionamento da racionalidade tecnocrática, das formas tradicionais de luta política, bem como a ênfase no lúdico, no cotidiano, no prazer, na força da imaginação." (RIOARTE, 1993, p. 2).

Considerava, portanto, como alternativos os jornais influenciados pela contra-cultura, movimento surgido nos Estados Unidos na década de 1950, que procurou revolucionar a poesia, a literatura, a música, as artes plásticas, muitas vezes discutindo-as sob um prisma existencial. Temas como misticismo, drogas, astrologia, vida alternativa, zen-budismo, o apelo ao on the road, no qual pontificavam os mitos norte-americanos Jack Keroauc e Allen Ginsberg, conquistaram incontáveis adeptos no Brasil. Luiz Carlos Maciel, que assinava uma coluna no Pasquim intitulada Underground (lançada em 1969), refutava aqueles que se posicionavam contra o movimento devido à sua origem estrangeira dizendo que a influência cultural "deve ser assimilada de forma crítica e só a compreensão, não a ignorância, vaidosa, torna a crítica possível." (MACIEL, 1973). O acervo conta com inúmeros órgãos representativos desse novo modo de ver e pensar a vida e a cultura tais como Flor do Mal, Rolling Stone, Navilouca, que são os mais conhecidos. Porém Kaos, Flops, Ta-Ta-Ta Jornal, Verbo Encantado, Vírgula, entre outros, tratam de temas análogos.

Ainda de acordo com o Centro:

Toda a produção independente/marginal/alternativa/nanica/emergente era, então, ou uma expressão de resistência - num momento em que os canais mais estabelecidos e sedimentados se viram fortemente bloqueados, em particular a imprensa - ou uma expressão do "desbunde" - que obviamente também tinha um sentido de resistência embora com características próprias; a literatura presenciou (em especial a poesia) o surgimento de uma linguagem veiculada através de novos produtos que começam a ganhar o rótulo de poesia marginal. Surgiram, assim, formas de produção e distribuição de bens culturais apoiados sobre o artesanal e o coletivo. Fato, que, por sua vez, abria todo um novo campo de pesquisa gráfica, visual - com forte ênfase no baixo custo e no uso de uma criatividade lúdica - um novo mercado - conseguido freqüentemente no trabalho direto do próprio produtor que, partindo da idéia de "venda agressiva", se tornava anunciante e vendedor de seu próprio produto - e mesmo um novo tipo de relação com o público. (RIOARTE, 
1993, p. 3).

Os principais adeptos da produção marginal e venda agressiva de que fala o Centro foram os jornais literários, vendidos nas ruas, bares, restaurantes, saídas de teatro e cinema. Eles constituem maioria absoluta no acervo. De acordo, ainda, com Centro de Imprensa Alternativa e Cultura Popular, quando os jornais de resistência democrática entraram em declínio, uma outra imprensa se afirmou nos anos 1980, criando profundas raízes na realidade social, cultural e política do país, a denominada imprensa sindical. Apesar de ser por muitos relegada a um segundo plano, desempenhou um papel muito importante como formadora de opinião junto a um amplo setor da nação, os trabalhadores e os funcionários das grandes indústrias e empresas estatais (RIOARTE, 1993, p. 4).

No acervo há inúmeros jornais publicados por sindicatos, alguns defendendo as causas dos trabalhadores, maiores salários, melhores condições de trabalho como Boca Maldita, órgão do Sindicato dos Empregados de Estabelecimentos Bancários do Rio de Janeiro; alguns, ainda, possuem orientação nitidamente de esquerda, político-sindical, como Alavanca, Jornal Popular Independente, com distribuição nacional; uns são informativos e alguns, ainda, literários e culturais, como Movimento Poetas da Praça, editado pela CUT/Bahia, trazendo poesias ao lado de artigos sobre mobilização da categoria.

Também os jornais e revistas publicados por estudantes figuram com algum destaque no acervo. O movimento estudantil está presente nesse conjunto documental através de periódicos que revelam a rebeldia e a contestação dos jovens nos denominados anos de chumbo. Uns são ligados a correntes do movimento estudantil, como Ibiúna; outros expressam o descontentamento dos diretórios acadêmicos com o status quo, bem como os debates que ocorrem no seu interior, como Viração, órgão predominantemente político do Diretório Acadêmico Tiradentes, da PUC /RJ; muitos são informativo-culturais, como Análise, órgão do Diretório Central das Universidades Mackenzie, de São Paulo; alguns, ainda, são dedicados a reflexões e discussões teóricas sobre as disciplinas dos cursos, como Espaço, dos estudantes de arquitetura de São Paulo; mas a maioria presente no acervo tem um caráter lítero-cultural, como o Caderno de Poetas, publicação do 
Centro Acadêmico Eco, e Cem Flores, do DCE da Universidade Federal de Minas Gerais.

O Centro preocupou-se, também, em refletir sobre a contribuição que a imprensa alternativa teria trazido para a sociedade brasileira e indagava:

\footnotetext{
Passada a década de 70, isto é, passados o fechamento e o "desbunde", qual o saldo da cultura alternativa? Basicamente essa parece ter aberto espaços para as múltiplas formas de organização a nível da sociedade civil, como por exemplo, associações de bairros, organização de cooperativas, além de ter posto em pauta temas de discussões tais como a questão das minorias culturais, étnicas e sexuais ou mesmo ter renovado velhas discussões como a crítica ao populismo. (RIOARTE, 1993, p. 3).
}

Segundo Ana Maria Colling, é a partir de 1970 que ocorre uma verdadeira revolução no mundo feminino, a questão da sexualidade, antes um tabu, passa a freqüentar os temas tratados nas revistas destinadas às mulheres, antes ocupadas com questões como moda, culinária e dicas para aprimorar as tarefas domésticas. Para essa especialista, o ano de 1975 representa um divisor de águas na luta feminina. Antes dedicadas a questionar a discriminação social, política e econômica, a discutir temas como sexualidade, contracepção, aborto, dupla jornada de trabalho, passam a atuar também politicamente, muitas delas tornando-se militantes e optando pela clandestinidade (COLLING, 1997, p. 45).

Jornais como Brasil Mulher, Mulher, O Sexo Finalmente Explícito, Mulherio, Nós Mulheres, Maria Maria trazem uma nova perspectiva para a afirmação da mulher em um mundo de ideologia nitidamente masculina. Entrava em cena a mulher militante, aquela que discutia os temas candentes da época, se posicionava, contestava. Um exemplo dessa tendência é o jornal Brasil Mulher que deu destaque nas suas páginas ao projeto de anistia proposto por D. Evaristo Arns e entra em campo fazendo coleta de assinaturas para apressá-la (O CURSO..., 1975, p. 1). Manifestase contra a censura que tirou de circulação o $\mathrm{n}^{\circ} 45$ do jornal Movimento, que trazia a matéria intitulada "O trabalho da mulher no Brasil", reivindicando a liberação na íntegra do material censurado (VOCÊ mulher, 1975, p. 8-9). Além dos assuntos políticos, o jornal debatia a presença da mulher no mercado de trabalho em igualdade com o homem, os direitos da mulher, a criação de creches, o 
planejamento familiar (A PROCURA..., 1978, p. 15). Nós Mulheres, aproximando-se as eleições municipais de 1976, convoca as mulheres a votar, para garantir o retorno ao estado de direito através das urnas (ELEIÇÕES, 1976, p. 8-9).

Nesse período também começam a surgir os movimentos de afirmação do homossexualismo. No acervo há vários jornais dedicados à causa. Entender (CENSURADO, 1977, p. 4) lança uma matéria bastante ousada para a época sobre casamento gay na Umbanda, tendo em vista o conservadorismo do regime militar. Lampião da Esquina, utilizando-se da Declaração Universal dos Direitos do Animal, proclamada pela Unesco, faz analogia com os direitos das minorias, que o jornal define como "um grupo sobre o qual a sociedade repressiva mantém seus tacões, mesmo que ele não seja minoritário, como as mulheres...(não são)". (LONTRAS..., 1978, p. 11). Há, ainda, neste conjunto documental, jornais publicados no exterior, tratando de várias temáticas. Entre eles, os que também defendiam o fim do preconceito sexual, como Pa'fuera, Sentinel, Sapho, etc.

Os militares, na tentativa de preservar a moral e os bons costumes segundo uma visão muito própria, conservadora e autoritária, acusavam os comunistas de quererem desestabilizar a família, pregando o amor livre, fazendo propaganda do sexo, da pornografia, ameaçando desintegrar a sociedade. Por isso, a repressão atingiu também os periódicos que defendiam interesses das minorias, das mulheres e dos gays. Lampião da Esquina foi enquadrado na Lei de Imprensa, acusado de atentado à moral e aos bons costumes. Várias foram as pressões que o jornal sofreu desde agosto de 1978: visitas matinais dos agentes do Departamento de Polícia Federal, solicitações arbitrárias como fiscalização da contabilidade, humilhação de serem os jornalistas fichados como criminosos. O processo contra o jornal foi arquivado em outubro de 1979, após parecer do Procurador da República que dizia: "No caso em exame, a publicação inquinada de ofensiva à moral pública pode ofender a moral de alguém, mas não de todos. Portanto, é relativo e não absoluto o conceito de moral daquele que condena essas publicações." (JUSTIÇA..., 1979, p. 1).

Integram o acervo periódicos como Porantim, que fez a cobertura do " $1{ }^{\circ}$ Congresso de Movimentos Índios de Sudamérica”, realizado no Peru (AMERÍNDIA..., 1980, p. 
1), Borduna, Nimuendaju, todos envolvidos na luta pelos direitos indígenas. Inúmeros são também os jornais que contestavam o regime por meio do humor e da sátira. Os mais famosos são o Pif-Paf, que surgiu um mês após o golpe de 1964, publicou apenas oito números, pois foi logo fechado pela censura, e o Pasquim, que chegou a ter 400 mil leitores, passou por diversos dissabores, inclusive com a prisão da maioria dos seus editores e colaboradores, mas conseguiu sobreviver por muito tempo e inclusive ser retomado e novamente fechado, agora por outras razões, no século 21. Pingente, Babel, Cabeça Feita, de linha anarquista, Gruta, de literatura e humor, Maturi, contendo textos literários num viés satírico são exemplos de periódicos humorísticos que integram essa série documental.

Portanto, pela seleção de periódicos, pelos objetivos e ações do Centro de Imprensa Alternativa e Cultura Popular, concluímos que, para esse órgão, integram a imprensa alternativa além dos periódicos que contestavam diretamente o regime de exceção, que constituíam veículos de movimentos e correntes de esquerda, todos os que não possuíam meios de comunicação de massa, que pensavam de forma independente, que não estavam ligados a esquemas governamentais ou econômicos e que não aceitavam o autoritarismo dominante não só na política, mas nos costumes, no comportamento, na linguagem, nos valores, propondo novos conteúdos e uma diagramação arrojada para a época.

Para organizar esse conjunto expressivo de periódicos o Centro de Imprensa Alternativa e Cultura Popular relacionou todos os jornais, revistas, cadernos, boletins, suplementos e folhas em um catálogo, trabalho coordenado por Leila Miccolis e Marcos Augusto Gonçalves, com a assistência de arquivo de Luís Moreira. Leila tinha comprovada experiência anterior, é jornalista, poeta e foi, inclusive, editora do jornal cultural Blocos e colaboradora de várias revistas e jornais alternativos como Cordão Galope Poético, uma publicação literária mimeografada, Trote, de poesia, Semente, publicação ecológica e naturista, entre outros.

O catálogo diferencia os periódicos intitulados de nanicos (em geral mimeografados ou em cópia xerox, com tiragens pequenas de folhas-ofício grampeadas) dos alternativos (tablóides ou mini-tablóides, de médio porte, muitos com esquema de distribuição nacional, inclusive em bancas). Além do formato, os 560 verbetes com 
feição enciclopédica trazem o número de páginas, local da publicação, datas de publicação, editora, editores, colaboradores, se a impressão é em preto e branco ou policrômica, tiragem e o perfil da publicação, ou seja, informações sobre se o periódico é político, literário, de gênero, de minorias, as principais matérias veiculadas, se contém ilustrações, fotos, charges etc. Com vistas a obter o máximo de informações, foram enviados questionários a todas as publicações da época, mas, mesmo assim, ainda permaneceram muitas lacunas como datas de publicação, local da edição, nomes incompletos dos colaboradores ou editores por não constarem dos expedientes dos jornais.

Ao empreendemos a classificação e notação dos periódicos para guarda e acondicionamento nas caixas, verificamos que 118 títulos indicados no catálogo do RIOARTE não constavam do acervo e 735 títulos de publicações não estavam relacionados no catálogo. Aqueles que foram criados após 1982 ou surgiram antes, mas só foram integrados ao acervo após esta data, não estão relacionados no primeiro catálogo. Por outro lado, as ausências são atribuídas a perdas ou descarte, pois este acervo permaneceu por muito tempo guardado sem contar com as condições de armazenamento prescritas pelas modernas técnicas de preservação.

Fez-se necessário, portanto, a elaboração de um segundo catálogo, nos moldes do anterior, reunindo todos os títulos existentes no acervo. Cumpre observar que adotamos a metodologia empregada na elaboração do catálogo inicial, pois consideramos que os verbetes contendo os dados essenciais sobre cada publicação facilitam em muito o trabalho do pesquisador. Em ambos, os jornais estão relacionados em ordem alfabética, mas na migração dos dados para o programa de software desenvolvido pela Assessoria de Informática da Secretaria Municipal das Culturas estão sendo observadas as normas arquivísticas. Portanto, embora ainda não disponível em meio eletrônico, em breve será possível consultar os jornais por título, data, espécie (nesta categoria foram agrupados sob as seguintes denominações: jornal, revista, boletim, cadernos, suplemento, folhas), por conteúdo ou descrição no site www.rio.ri.gov.br/arquivo. Assim, graças ao trabalho pioneiro da equipe do RIOARTE - somado ao trabalho desenvolvido pelo corpo técnico do Arquivo da Cidade - temos hoje todo o conjunto documental Imprensa Alternativa identificado, classificado, acondicionado adequadamente e aberto à consulta pública 
no prédio da instituição, localizado à rua Amoroso Lima, 15, Cidade Nova, Rio de Janeiro, RJ., tel.: (21) 2273-4582 / 2273-3141.

A partir das informações veiculadas nos verbetes foi possível estabelecer algumas estatísticas capazes de dimensionar este acervo. A primeira refere-se às datas-limite deste conjunto documental. Existem periódicos datados de 1955 até 2002, mas a maior incidência está nas décadas de 1970 e 1980, justamente o período mais autoritário da ditadura civil-militar. A maior parte dos jornais foi editada no Rio de Janeiro, São Paulo e Minas Gerais, mas há publicações de quase todos os estados do país, excluindo Amapá, Rondônia e Roraima. Surpreende o fato de que no acervo constem jornais de 131 cidades - capitais e do interior - que editaram algum tipo de periódico, um jornal estudantil de 1 ou 2 páginas, de textos ou de poesia. Se ainda hoje o país conta com um número expressivo de analfabetos e de alfabetizados funcionais, podemos imaginar a situação há 30 anos atrás. No entanto, temos um quantitativo que revela a capilaridade da imprensa naquele período e um claro sintoma da necessidade de alguns segmentos da sociedade de se fazerem ouvir, uma vez que a redução do espaço público para a discussão e veiculação de idéias era uma realidade. Este é um fenômeno que merece ser estudado, pois, revela que a despeito das dificuldades citadas existia um certo vigor das letras no nosso país, que houve movimentos de vanguarda na literatura e que grupos de escritores e poetas deram grande importância à divulgação de suas reflexões e criações literárias.

O fato é que para os historiadores que se debruçam sobre este período, para aqueles que estudam comunicação, imprensa, literatura, artes, cultura sob o ponto de vista da contestação aos padrões estéticos e morais que prevaleciam naqueles anos, a importância deste acervo é inquestionável.

Falando sobre o papel da imprensa para o entendimento dos contextos históricos, Alberto Dines diz que "jornalismo e historiografia são primos - quando se pratica um deles com proficiência, chega-se inevitavelmente ao outro." (DINES, 1986, p. 19). Podemos, portanto, afirmar, sem medo de errar, que aonde a imprensa não existe, o historiador se sente desfalcado de uma de suas principais fontes. 


\section{Referências Bibliográficas}

ANDRADE, Jefferson; SILVEIRA, Joel. Um jornal assassinado: a última batalha do Correio da Manhã. Rio de Janeiro: José Olympio, 1991.

AZEVEDO, Reinaldo. O fim da Primeira Leitura, um recomeço - Observatório da Imprensa - Entrevista concedida a Luís Antônio Magalhães, 20 julh. 2006. Disponível em http://observatorio.ultimosegundo.ig.br/artigos.asp?cod=386IMQ003. Acesso em 23 jul. 2006.

BARROS, Patrícia Marcondes de. Stultíferas Navis: a imprensa alternativa como antídoto ao regime militar. In: SEMANA DA HISTÓRIA, 22., 2004, Assis. O golpe de 1964 e os dilemas do Brasil contemporâneo: [anais eletrônicos]. Unesp: Assis, 2004. Disponível em: http:// www.assis.unesp.br/semanadehistoria. Acesso em: 22 maio 2006.

CALLADO, Antônio. Prefácio. In: MARCONI, Paolo. A censura política na imprensa brasileira (1968-1978). São Paulo: Global, 1980.

COLLING, Ana Maria. A resistência da mulher à ditadura militar no Brasil. Rio de Janeiro: Record; Rosa dos Ventos, 1997.

DINES, Alberto - O papel do jornal. Uma releitura. São Paulo: Summus, 1986.

KUCINSKI, Bernardo. Jornalistas e revolucionários nos tempos da imprensa alternativa. São Paulo: EDUSP, 2003.

KUSHNIR, Beatriz. Cães de aluguel. São Paulo: Boitempo, 2004.

MACIEL, Luis Carlos. Nossa consciência, jornalismo contra cultural (1970-1972). Rio de Janeiro: Eldorado, 1973.

MARCONI, Paolo. A censura política na imprensa brasileira (1968-1978). São Paulo: Global, 1980.

PEREIRA, Moacir. O golpe do silêncio. São Paulo: Global, 1984.

STEPHANOU, Alexandre Ayub. Censura no regime militar e militarização das artes. Porto Alegre: Pontifícia Universidade Católica/RS, 2001. (Coleção História, 44).

\section{Relatórios}

RIOARTE (Brasil). Secretaria Municipal de Cultura. Prefeitura do Rio de Janeiro. Relatório 1980-1982. Rio de Janeiro, 1993. (Datilografado)

\section{Artigos de Jornais}


AMERÍNDIA contra o imperialismo. Porantim, Manaus, v. 2, n. 17, p. 1, abr. 1980.

CADA vez mais difícil ter uma 'Opinião' em 'Movimento'. Lampião, Porto Alegre, v. 1, n. 1, p. 1, 10.mar.1976.

CENSURADO - homossexuais casam na umbanda. Entender, São Paulo, n. 5, p. 4, 24 dez. 1977.

O CIRCO das eleições. O Trabalho, São Paulo, n. 10, p. 1, 26.set. a 10 out. 1978.

O CURSO do movimento feminino pela anistia. Brasil Mulher, v. 1, n. 0, p. 1, 9 out.1975.

ELEIÇÕES. Nós Mulheres, São Paulo, n. 3, p. 8-9, nov./dez.1976.

HORA de censurar a censura. Crítica, Rio de Janeiro, v. 1, n. 47, p. 1, 30 jun a 6 jul. 1975.

JUSTIÇA arquiva inquérito contra Lampião. Lampião da Esquina, Rio de Janeiro, v. 2, n. 18, p. 1, nov. 1979.

LONTRAS, piranhas, ratos, veados. Lampião da Esquina, Rio de Janeiro, v. 1, n. 0, abr. 1978. Ed. Experimental, p. 11.

O PARTIDO dos Trabalhadores avança. O Trabalhador, São Paulo, n. 3, p. 1, 31out. 1979.

À PROCURA da igualdade perdida. Brasil Mulher, Londrina, v. 3, n. 12, p. 15, maio 1978.

O RITUAL da aflição nos cárceres políticos. De Fato, Belo Horizonte, v. 3, n. 21, p. 17, mar.1978.

VOCÊ mulher. Brasil Mulher, Londrina, v. I, n. 2, p. 8-9, 1975.

\section{Jornais consultados}

ALAVANCA - Jornal Popular Independente. São Gonçalo, maio 1979. Edição Extra.

ANÁLISE. São Paulo: Diretório Central dos Estudantes Universitários da Universidade Mackenzie, n. 16, 1977.

BABEL - Jornal de Humor. Rio de Janeiro, n. 1, out. 1978.

BOCA MALDITA. Rio de Janeiro: Sindicato dos Empregados de Estabelecimentos Bancários do Município do Rio de Janeiro. (SEEBE- RJ), v. 1, n. 2, set. 1980.

BOCA DA NOITE. Rio de Janeiro, n. 2, 1980.

BORDUNA. Rio de Janeiro: Comissão Pró-Índio, [s.d.].

CABEÇA FEITA. Rio de Janeiro, n. 1, 1980.

CADERNO DE POETAS. Rio de Janeiro: CAECO, n. 3, 1977. 
CEM FLORES. Belo Horizonte: Diretório Central dos Estudantes da UFMG, n. 1, set./out. 1978.

CONTESTADO. Florianópolis, n. 3, mar. 1978.

EX. São Paulo, n. 6, set. 1974.

FLOR DO MAL. Rio de Janeiro: O Pasquim, n. 3, 1971.

ESPAÇO. São Paulo: Grupo de Estudantes de Arquitetura de São Paulo, 1980.

FLOPS. [s....], [s.n.], 1974.

GRUTA. Nova Iguaçu: Grupo Tangerina, [s.d.].

IBIÚNA. [s.I.]:Revista de uma corrente do movimento estudantil, [s.d.]

O INIMIGO DO REI. Salvador: Grupo de alunos da UFBA, n. 5, abr./maio 1979.

MARIA MARIA. Londrina: Jornal do grupo do Brasil Mulher, n. 1, maio/jun. 1984.

MATURI. Natal: [s.n.], set. 1976. Exemplar D.

MOVIMENTO POETAS DA PRAÇA. Salvador: Central Única dos Trabalhadores - Seção Bahia, [s.d.].

MULHER. São José dos Campos, [s.d.]. I Semana da Mulher.

MULHERIO. São Paulo: Fundação Carlos Chagas, mar./abr. 1981.

NIEMANDAJU. [s.I.]: Boletim da Comissão Pró-Índio, n. 1, jan./fev.1979

NAVILOUCA. Rio de Janeiro, [s.d.].

PA'FUERA. San Juan: Comunidade de Orgulho Gay, [s.d.].

PASQUIM. Rio de Janeiro, n. 294, 24 fev. 1975.

PIF-PAF. Rio de Janeiro, n. 1, 27 ago. 1964.

PINGENTE. Osasco, n. 2, 1981.

POLITIKA - um jornal sem preconceitos. Rio de Janeiro, n. 1, 22 a 28 out. 1971.

ROLLING STONE. Rio de Janeiro, [s.d.]. 
SAPHO. Londres, [s.d.].

SENTINEL. San Francisco, EUA, [s.d.].

O SEXO FINALMENTE EXPLícITO. Rio de Janeiro, n. 1, set. 1983.

TA-TA-TA JORNAL. Rio de Janeiro, n. 1, dez. 1976.

VERBO ENCANTADO. Salvador: Tribuna da Bahia; Rio de Janeiro, 1971-72, jun. 1972.

VIRAÇÃO. Rio de Janeiro: Diretório Acadêmico Tiradentes da PUC, n. 2, mar. 1972.

VÍRGULA. Rio de Janeiro, 1967.

* Historiadora. Mestre em História (Universidade Federal Fluminense). Gerente de Pesquisa do Arquivo Geral da Cidade do Rio de Janeiro - Secretaria Municipal das Culturas - Prefeitura da Cidade do Rio de Janeiro. shorta@pcri.ri.gov.br 